\title{
GBD 2015: migraine is the third cause of disability in under $50 \mathrm{~s}$
}

Timothy J. Steiner ${ }^{1,2^{*}}$, Lars J. Stovner ${ }^{1,3}$ and Theo $\operatorname{Vos}^{4}$

Keywords: Headache disorders, Migraine, Tension-type headache, Medication-overuse headache, Burden of disease, Disability, Public health, Global Burden of Disease study, Global Campaign against Headache

\section{How much headache is there in the world?}

The answer depends on how headache is measured. The question, however, is an important one. It is at the basis of health policy, prioritisation and the due allocation of health resources to headache care and the mitigation of its clinical sequelae. From this perspective, prevalence alone is not highly informative: it is the burdens arising from headache disorders that dictate their impact on public health. These burdens are multiple, diverse and partly invisible [1]. Methods do not yet exist to measure them all [1], but the focus meanwhile has been on disability. It is to this, primarily, that health, quality of life, productivity and financial security are hostage.

So how much headache-related disability is there in the world? Estimates of disability due to disease are a principal objective of the Global Burden of Disease (GBD) studies, performed reiteratively since 1990 and described now as "the most comprehensive worldwide observational epidemiological study to date" [2]. GBD 1990 was initiated by the World Bank and GBD 2000 by the World Health Organization; subsequently, GBD has been led by the Institute for Health Metrics and Evaluation [3], and financially supported by the Bill and Melinda Gates Foundation. GBD uses a number of metrics: among these, disability is measured in years lived with disability (YLDs) and early mortality in years of life lost (YLLs); disability-adjusted life years (DALYs) are the summation of YLDs and YLLs. Migraine first featured in GBD 2000 [4], and over 13 years ascended the ranks of top causes of YLDs worldwide, from $19^{\text {th }}$ in GBD 2000 [4] to seventh in GBD $2010[5,6]$ and sixth in GBD

\footnotetext{
* Correspondence: t.steiner@imperial.ac.uk

${ }^{1}$ Department of Neuroscience, Norwegian University of Science and

Technology (NTNU), Edvard Griegs Gate, Trondheim, Norway

${ }^{2}$ Division of Brain Sciences, Imperial College London, London, UK

Full list of author information is available at the end of the article
}

2013 [7, 8]. Meanwhile, of the other headache disorders of public-health importance, tension-type headache (TTH) was introduced in GBD 2010 [5] and medicationoveruse headache $(\mathrm{MOH})$ in GBD 2013 (and ranked 18 highest cause of YLDs) [7]. GBD 2013 established headache disorders collectively as the third highest cause of YLDs [8].

The rise of migraine over these years is not indicative of increasing prevalence. While GBD is dependent on data from the entire world, headache epidemiology is a still-developing science [9]. Very large knowledge gaps existed in 2000, particularly in regions outside the Americas and Western Europe [10]. Filling these gaps became the first priority of the Global Campaign against Headache after its launch in 2004 [11-13]. Collaborating in all subsequent GBD studies, the Global Campaign has informed them by conducting new population-based surveys in Georgia, Russia, China, Nepal, South India, Saudi Arabia, Pakistan, Zambia, Ethiopia and Morocco [14]. This concerted data-collection effort has allowed much better estimates from GBD 2010 onwards. With empirical data replacing many of the assumptions underlying the earlier GBD estimates, and an approach to YLD calculation based on prevalence rather than incidence and duration as in GBD 2000, estimates became possible by country rather than by large world regions.

GBD 2015 has now been published [15, 16]. In this latest iteration, a more systematic hierarchy has been adopted in the grouping of related causes of DALYs. Non-communicable disorders, at level 1 , include neurological disorders at level 2; within the latter reside the individual headache disorders (migraine, TTH and $\mathrm{MOH})$ at both levels 3 and 4 . Future iterations of GBD may more logically group the headache disorders together at level 3 , as we have done in the following analysis. 
Headache disorders account for more DALYs than all other neurological disorders combined (including dementias), despite having no association with mortality [16]. Because of this latter fact, the comparative impact of headache disorders on public health is better indicated by YLDs, taking disability but not mortality into account. At level 3, headache disorders occupy sixth place among the leading causes of disability, varying between $3^{\text {rd }}$ and $7^{\text {th }}$ in regions around the world [15] (Table 1). While this demotion by three places compared with GBD 2013 [8] may appear as a diminution, this is not so: successive iterations of GBD, increasingly better informed, have shown total YLDs attributed to headache disorders rising consistently. Rather, at level 3, headache disorders are displaced by GBD 2015 groupings of low back and neck pain, which clearly takes top place, sense organ diseases in second place and skin diseases in fifth [15].

At level 4, migraine on its own is the $21^{\text {st }}$ leading cause of DALYs worldwide, tenth in Western Europe and sixth worldwide in the age group 25-39 years [16]. Migraine, TTH and $\mathrm{MOH}$ are all diseases mainly affecting young adults: in terms of YLDs, they remain collectively in third place among level-3 causes in both males and females aged 15-49 years [15] (Table 1). This is due largely to migraine, which on its own, at level 4, is third in this age group in both genders (Table 2). In present estimates, migraine, estimated to affect 959 million people worldwide, emerges by a long distance as the most disabling headache disorder at population level [15]. TTH, despite being the second most prevalent disorder in the world (behind dental caries) [7], adds much less to population disability estimates because a low disability weight of 0.036 (on a scale of $0-1$ ) is accorded to the headache of TTH compared with 0.434 for the ictal state of migraine [17]. $\mathrm{MOH}$ is recognised as far more disabling at an individual level but, with its prevalence still very poorly estimated in many regions [18, 19], it stays ranked as $18^{\text {th }}$ cause of YLDs in GBD 2015 [15].

There can be no doubt that migraine is a major contributor to public ill health in all countries, climes and cultures. Table 2 shows it consistently ranked fifth to eighth among the top causes of disability in all world regions. Further, the notion that migraine is a disease preferentially affecting rich industrialised nations is dispelled by the comparison in Table 2 between low- and high-income countries. It is worth adding here that GBD currently considers only the disability burden associated with the ictal state of headache disorders, whereas there is evidence of interictal burden in a considerable proportion of people with migraine and in a small proportion of people with TTH [20]. The significance of interictal burden is that, although it may be at relatively low level, it is present for longer periods of time than ictal burden. With new data indicating that interictal disability in headache disorders is real and measurable [20], future iterations of GBD should consider adding this component of disability.

Table 1 Years lived with disability (YLDs) attributed to all headache disorders ${ }^{\mathrm{a}}$ by gender, age and world region

\begin{tabular}{|c|c|c|c|c|c|}
\hline Region & Gender & Age range (years) & YLDs per 100,000 & $\%$ of total & Rank $^{\mathrm{b}}$ \\
\hline \multirow[t]{9}{*}{ Global } & Both & All & 601 & 5.61 & 6 \\
\hline & & $15-49$ & 813 & 8.13 & 3 \\
\hline & & $50-69$ & 732 & 4.67 & 6 \\
\hline & M & All & 438 & 4.35 & 7 \\
\hline & & $15-49$ & 597 & 6.49 & 3 \\
\hline & & $50-69$ & 516 & 3.25 & 6 \\
\hline & $\mathrm{F}$ & All & 767 & 6.76 & 5 \\
\hline & & $15-49$ & 1,036 & 9.59 & 3 \\
\hline & & $50-69$ & 940 & 5.58 & 6 \\
\hline Western Europe & Both & All & 783 & 6.32 & 4 \\
\hline Central and Eastern Europe and Central Asia & & & 778 & 6.41 & 4 \\
\hline North Africa and Middle East & & & 702 & 6.80 & 3 \\
\hline South Asia & & & 730 & 6.55 & 5 \\
\hline SE and East Asia and Oceania & & & 443 & 4.48 & 7 \\
\hline High-income Asia Pacific & & & 607 & 5.34 & 5 \\
\hline High-income North America & & & 646 & 5.01 & 6 \\
\hline Latin America and Caribbean & & & 688 & 6.76 & 4 \\
\hline Sub-Saharan Africa & & & 449 & 4.27 & 6 \\
\hline
\end{tabular}

${ }^{a}$ Migraine, tension-type headache and medication-overuse headache

bamong the top level-3 causes of disability in GBD 2015 
Table 2 Years lived with disability (YLDs) attributed to migraine by gender, age, world region and country income

\begin{tabular}{|c|c|c|c|c|c|}
\hline Region & Gender & Age range (years) & YLDs per 100,000 & $\%$ of total & Rank $^{a}$ \\
\hline \multirow[t]{9}{*}{ Global } & \multirow[t]{3}{*}{ Both } & All & 446 & 4.17 & 7 \\
\hline & & $15-49$ & 615 & 6.16 & 3 \\
\hline & & $50-69$ & 495 & 3.03 & 8 \\
\hline & \multirow[t]{3}{*}{ M } & All & 311 & 3.09 & 8 \\
\hline & & $15-49$ & 432 & 4.70 & 3 \\
\hline & & $50-69$ & 324 & 2.05 & 13 \\
\hline & \multirow[t]{3}{*}{$\mathrm{F}$} & All & 584 & 5.15 & 4 \\
\hline & & $15-49$ & 805 & 7.46 & 3 \\
\hline & & $50-69$ & 659 & 3.91 & 7 \\
\hline Western Europe & \multirow[t]{9}{*}{ Both } & \multirow[t]{9}{*}{ All } & 580 & 4.69 & 5 \\
\hline Central and Eastern Europe and Central Asia & & & 515 & 4.25 & 6 \\
\hline North Africa and Middle East & & & 498 & 4.83 & 5 \\
\hline South Asia & & & 569 & 5.11 & 5 \\
\hline SE and East Asia and Oceania & & & 334 & 3.39 & 8 \\
\hline High-income Asia Pacific & & & 434 & 3.82 & 5 \\
\hline High-income North America & & & 473 & 3.68 & 8 \\
\hline Latin America and Caribbean & & & 497 & 4.89 & 7 \\
\hline Sub-Saharan Africa & & & 312 & 3.12 & 6 \\
\hline \multirow[t]{3}{*}{ All low-income countries } & Both & \multirow[t]{3}{*}{ All } & 314 & 3.18 & 6 \\
\hline & M & & 227 & 2.41 & 8 \\
\hline & $\mathrm{F}$ & & 400 & 3.88 & 5 \\
\hline \multirow[t]{3}{*}{ All high-income countries } & Both & \multirow[t]{3}{*}{ All } & 502 & 4.09 & 6 \\
\hline & M & & 296 & 2.62 & 7 \\
\hline & $\mathrm{F}$ & & 700 & 5.31 & 4 \\
\hline
\end{tabular}

among the top level-4 causes of disability in GBD 2015

Where to next? If future GBD studies group the headache disorders together at level 3, they might consider including neck pain in this grouping rather than with low back pain: the last is markedly different from neck pain not only in its clinical sequelae but also aetiologically, whereas how much neck pain is actually secondary to headache? Meanwhile it is still not known how much headache - or headache-related disability - there is in the world. There are still large data gaps to be filled, particularly with regard to $\mathrm{MOH}$, which only recently has been included as a separate entity in population-based studies $[18,19]$. The Global Campaign has further studies underway or planned: in Guatemala, Peru, Nigeria, Uganda, Kuwait, North India, Sri Lanka and Mongolia [14]. GBD estimates of global averages properly take into account all available data, but published surveys are up to 30 years old, and use a variety of ascertainment methods [10]. Crude adjustments are relied upon to correct for measurement biases arising from less than ideal study methods or questionable case definitions. Global Campaign studies use standardised and higher quality methodology [9]. With the single exception of China, all of them so far performed have produced national estimates greater than GBD's mean global estimates $[6,8]$. As the new studies continue to feed data into future iterations of GBD, it is inevitable that the proportion of global disability correctly attributed to headache will continue to rise.

The importance of this measure is that it serves as a needs assessment, marking the existence of a very large burden of ill health to inform health policy in countries and regions the world over. GBD measures disease burden as it is - alleviated by whatever treatments are made available. The persistence of this heavy headache burden is a clear signal of continuing health-care failures that must be addressed [21, 22].

Authors' contribution

All authors read and approved the final manuscript.

\section{Competing interests}

TJS and LS are Directors and Trustees of Lifting The Burden, a UK-registered non-governmental organization conducting the Global Campaign against Headache in official relations with the World Health Organization, and were Global Burden of Disease Study 2015 collaborators as GBD Experts on headache disorders. TV is funded by the Bill and Melinda Gates Foundation. 


\section{Author details}

'Department of Neuroscience, Norwegian University of Science and Technology (NTNU), Edvard Griegs Gate, Trondheim, Norway. ${ }^{2}$ Division of Brain Sciences, Imperial College London, London, UK. ${ }^{3}$ Norwegian Advisory Unit on Headache, Department of Neurology and Clinical Neurophysiology, St Olavs University Hospital, Trondheim, Norway. ${ }^{4}$ Institute of Health Metrics and Evaluation (IHME), University of Washington, Seattle, WA, USA.

Received: 7 November 2016 Accepted: 10 November 2016

Published online: 14 November 2016

\section{References}

1. Steiner TJ, Gururaj G, Andrée C, Katsarava Z, Ayzenberg I, Yu SY, Al Jumah M, Tekle-Haimanot R, Birbeck GL, Herekar A, Linde M, Mbewe E, Manandhar K, Risal A, Jensen R, Queiroz LP, Scher Al, Wang SJ, Stovner LJ (2014) Diagnosis, prevalence estimation and burden measurement in population surveys of headache: presenting the HARDSHIP questionnaire. J Headache Pain 15:3

2. The Lancet, at http://www.thelancet.com/gbd. Accessed 29 Oct 2016.

3. Institute for Health Metrics and Evaluation. Global Burden of Disease (GBD), at http://www.healthdata.org/gbd. Accessed 29 Oct 2016.

4. World Health Organization (2001) The world health report 2001. WHO, Geneva, pp 19-45

5. Vos T, Flaxman AD, Naghavi M, Lozano R, Michaud C, Ezzati M, Shibuya K Salomon JA, Abdalla S, Aboyans V, Abraham J, Ackerman I, Aggarwal R, Ahn SY, Ali MK, Alvarado M, Anderson HR, Anderson LM, Andrews KG, Atkinson C, Baddour LM, Bahalim AN, Barker-Collo S, Barrero LH, Bartels DH, Basáñez MG, Baxter A, Bell ML, Benjamin EJ, Bennett D et al (2012) Years lived with disability (YLD) for 1160 sequelae of 289 diseases and injuries 1990-2010: a systematic analysis for the Global Burden of Disease Study 2010. Lancet 380: 2163-2196

6. Steiner TJ, Stovner LJ, Birbeck GL (2013) Migraine: the seventh disabler. $J$ Headache Pain 14:1

7. Vos T, Barber RM, Bell B, Bertozzi-Villa A, Biryukov S, Bolliger I, Charlson F, Davis A, Degenhardt L, Dicker D, Duan L, Erskine H, Feigin VL, Ferrari AJ, Fitzmaurice C, Fleming T, Graetz N, Guinovart C, Haagsma J, Hansen GM, Hanson SW, Heuton KR, Higashi H, Kassebaum N, Kyu H, Laurie E, Liang X, Lofgren K, Lozano R, MacIntyre MF, Moradi-Lakeh M, Naghavi M, Nguyen G, Odell S, Ortblad K et al (2015) Global, regional, and national incidence, prevalence, and years lived with disability for 301 acute and chronic diseases and injuries in 188 countries, 1990-2013: a systematic analysis for the Global Burden of Disease Study 2013. Lancet 386:743-800

8. Steiner TJ, Birbeck GL, Jensen RH, Katsarava Z, Stovner LJ, Martelletti P (2015) Headache disorders are third cause of disability worldwide. J Headache Pain 16:58

9. Stovner LJ, Al Jumah M, Birbeck GL, Gururaj G, Jensen R, Katsarava Z, Queiroz LP, Scher Al, Tekle-Haimanot R, Wang SJ, Steiner TJ (2014) The methodology of population surveys of headache prevalence, burden and cost: Principles and recommendations from the Global Campaign against Headache. J Headache Pain 15:5

10. Stovner LJ, Hagen K, Jensen R, Katsarava Z, Lipton R, Scher Al, Steiner TJ, Zwart J-A (2007) The global burden of headache: a documentation of headache prevalence and disability worldwide. Cephalalgia 27:193-210

11. Steiner TJ (2004) Lifting the burden: the global campaign against headache. Lancet Neurol 3:204-205

12. Steiner TJ (2005) Lifting The Burden: the global campaign to reduce the burden of headache worldwide. J Headache Pain 6:373-377

13. Steiner TJ, Birbeck GL, Jensen R, Katsarava Z, Martelletti P, Stovner $\sqcup$ (2010) Lifting The Burden: the first 7 years. J Headache Pain 11:451-455

14. Lifting The Burden: the Global Campaign against Headache, at http:// www.l-t-b.org. Accessed 29 Oct 2016.

15. GBD 2015 Disease and Injury Incidence and Prevalence Collaborators (2016) Global, regional, and national incidence, prevalence, and years lived with disability for 310 diseases and injuries, 1990-2015: a systematic analysis for the Global Burden of Disease Study 2015. Lancet 388:1545-1602

16. GBD 2015 DALYs and HALE Collaborators (2016) Global, regional, and national disability-adjusted life-years (DALYs) for 315 diseases and injuries and healthy life expectancy (HALE), 1990-2015: a systematic analysis for the Global Burden of Disease Study 2015. Lancet 388:1603-1658

17. Salomon JA, Vos T, Hogan DR, Gagnon M, Naghavi M, Mokdad A, Begum N, Shah R, Karyana M, Kosen S, Farje MR, Moncada G, Dutta A, Sazawal S, Dyer
A, Seiler J, Aboyans V, Baker L, Baxter A, Benjamin EJ, Bhalla K, Bin Abdulhak A, Blyth F, Bourne R, Braithwaite T, Brooks P, Brugha TS, Bryan-Hancock C, Buchbinder R, Burney P, Calabria B, Chen H, Chugh SS, Cooley R, Criqui MH et al (2012) Common values in assessing health outcomes from disease and injury: disability weights measurement study for the Global Burden of Disease Study 2010. Lancet 380:2129-2143

18. Westergaard ML, Holme Hansen E, Glümer C, Olesen J, Jensen RH (2014) Definitions of medication-overuse headache in population-based studies and their implications on prevalence estimates: A systematic review. Cephalalgia 34:409-425

19. Steiner TJ (2014) Can we know the prevalence of MOH? Cephalalgia 34: 403-404

20. Lampl C, Thomas H, Stovner LJ, Tassorelli C, Katsarava Z, Laínez JMA, Lantéri-Minet M, Rastenyte D, Ruiz de la Torre E, Andrée C, Steiner TJ (2016) Interictal burden attributable to episodic headache: findings from the Eurolight project. J Headache Pain 17:9

21. World Health Organization, Lifting The Burden (2011) Atlas of headache disorders and resources in the world 2011. WHO, Geneva

22. Steiner TJ, Stovner LJ, Dua T, Birbeck GL, Jensen R, Katsarava Z, Martelletti $P$, Saxena S (2011) Time to act on headache disorders. J Headache Pain 12: 501-503

\section{Submit your manuscript to a SpringerOpen ${ }^{\circ}$ journal and benefit from:}

- Convenient online submission

- Rigorous peer review

- Immediate publication on acceptance

- Open access: articles freely available online

- High visibility within the field

- Retaining the copyright to your article

Submit your next manuscript at $>$ springeropen.com 